\title{
"Not Three Gods, but One" - Why Reductionism Does Not Serve Our Theological Discourse
}

\author{
By Finley Lawson*
}

The triune nature of God is one of the most complex doctrines of Christianity, and its complexity is further compounded when one considers the incarnation. However, many of the difficulties and paradoxes associated with our idea of the divine arise from our adherence to reductionist ontology. I will argue that in order to move our theological discourse forward, in respect to divine and human nature, a holistic interpretation of our profession of faith is necessary. The challenge of a holistic interpretation is that it questions our ability to make any statement about the genuine, ontological individuation of persons (both divine and human), and in doing so raises the issue of whether we are ontologically bound to descend to a form of pan(en)theism. In order to address the "inevitable" slide in to pan(en)theism, I will examine the impact of two forms of holistic interpretation, Boolean and Non-Boolean, on our understanding of the world. I tentatively examine the kind of Trinitarian relations that may be allowed within a world governed by Boolean holism.

\section{Introduction}

Ayala highlights three main forms of reductionism: methodological, ontological and epistemological, ${ }^{1}$ and although other forms such as causal reductionism have been brought in to our terminology in more recent years, the majority of this paper will focus on the need to move away from ontological reductionism $^{2}$. Two of the most central doctrines of the Christian faith - the incarnation and the Trinity - are also the most complex, and their complexity stems from the fact that they ask the believer to comprehend something that is both profoundly divided and intrinsically united. Whilst it may be tempting to hide behind the notion of "divine mystery" or to echo Wittgenstein and claim "whereof one cannot speak thereof one must be silent," 3 then we seem to be acceding to the argument, at least implicitly, that the features of God "are beyond our reach, then only two possibilities remain: either this "something" [God] is altogether unknowable, and "pure $\mathrm{X}$," or it is such that we can get, or guess, some knowledge about it, but

${ }^{*}$ PhD Student, Canterbury Christ Church University, UK.

1. Francisco J. Ayala, "Biological Reductionism," in Self-Organizing Systems, ed. F. Eugene Yates, Alan Garfinkel, Donald O. Walter, and Gregory B. Yates (New York: Springer, 1987).

2. Ontological reductionism is the notion that complex objects can be reduced to objects, events, or properties that are real world items rather than representations of items in the world. This is often contrasted to relational reductionism in which complex objects are reduced to representational entities such as models or theories.

3. Ludwig Wittgenstein, Tractatus Logico-Philosophicus, trans. C. K. Ogden (London: Edinburgh University Press, 1922), 23. Retrieved from goo.g1/EoycUy. 
merely general or merely allegorical."4 However, such an assumption, even if it is implicit, seems to lead to the ultimate conclusion that "the reflective attempt called "theology," to explicate the religious faith in words, is an altogether mistaken endeavour." 5 Yet, Christianity does not believe this; rather, it is a faith that proudly and explicitly demarks what it believes through professions of faith and because of this, theologians have set out to try and comprehend how we are to understand division in unity whether that rests in the hypostatic union or the nature of a Triune God. It is in this space, in trying to wrestle with complex entities, that reductionism has found itself firmly engrained into our theological discourse.

\section{The Problem of Reductionism}

In this paper I examine the role that holistic ontology ${ }^{6}$ may play in helping us to reframe our theological metaphysics, and raise some tentative suggestions as to this new theological landscape may look and how it can preserve a doctri-nally relevant understanding of a Trinitarian God. Whilst issues can be raised with adopting a reductionist methodological ${ }^{7}$ approach to theological issues, the focus of this paper rests in highlighting some of the issues raised by ontological reductionism and how these may be resolved by adopting a holistic approach.

The problem of reductionism is perhaps best highlighted through consideration of the incarnation. It is possible to outline eight metaphysical models of the incarnation that explain Christ's humanity and divinity in a way that unites the three concrete objects God the Son (GS), a human body (B), and (possibly) a human soul (S) without falling afoul of heresy. For the purposes of this paper, it is enough to note that these models fall in to two broad categories: those that say God the Son became wholly or partially constituted by matter (materialist Christologies) and those in which God the Son became or was constituted by a soul or something "relevantly like a soul" (dualist Christologies). ${ }^{8}$ Whilst it is possible to make finer distinctions, the key thing to

4. Bernard d' Espagnat, Veiled Reality: An Analysis of Present-Day Quantum Mechanical Concepts (Boca Raton, Florida, United States: CRC Press, 2003), 355.

5. John Macquarrie, God Talk: Examination of the Language and Logic of Theology (London: SCM-Canterbury Press, 1970), 24.

6. Ontological holism, in its broadest sense, refers to a version of metaphysical holism that states that some objects are not composed of basic physical parts. i.e., it stands in opposition to ontological reductionism.

7. Methodological reductionism is the process of investigating a complex issue such as the incarnation by breaking it down in to separate smaller aspects or components that can be more easily investigated in relation to the incarnation this often result in the incarnation being investigated insolation from the pre and post incarnate existence of the son of God.

8. Brian Leftow, "The Humanity of God," in The Metaphysics of the Incarnation, ed. Anna Marmodoro and Jonathan Hill (Oxford: Oxford University Press, 2011). 
note is that there are three main issues in dealing with the incarnation in a reductionist ontology: materialism, mind-body interaction and heresy.

Even if one is willing to accept a materialist metaphysics, in respect to human persons, the issue is hugely compounded by the unique nature of the incarnation. The incarnation asks believers to understand that an immaterial object (preexistence God the Son) becomes a material object. Such a transforma-tion seems not only impossible to conceptualise, but also to show complete disregard for the principle of Conservation of Mass, which states that in a closed system the mass of the system must remain constant over time, as system mass cannot change quantity. If we are to believe that immaterial Christ becomes material, then this would seem to require the creation of a massive amount of matter within a seemingly closed system that is our universe (obviously, this interpretation is dependent upon whether God is viewed to be inside or outside of this "closed system" - a timeless model of God may present more problems in this instance than a model which allows for God to be within our time).

The problem of a dualist ontology, in which mind and matter are completely separate and distinct substances, is how or even if it is possible for mind and matter to interact. Just as it seems impossible for something to move from being an immaterial to a material object, so it also seems impossible for mind and matter to have a genuinely causal interaction. If such an interaction is not possible, we end up at a Rylesian "ghost in the machine" situation where the mind is caus-ally ineffectual. If the mind and body of ordinary persons are unable to causally interact it seems equally implausible that the immaterial God the Son would be able to interact with a material human body (and has theological implications beyond the incarnation).

Finally, it is necessary to establish a metaphysics in which the component parts join together to form one person with two discrete natures. The Incarnate Son of God must be both fully human and fully divine, with two natures that are distinct enough to be separate, but not so separated that Jesus becomes two persons in one body. In trying to understand the incarnation within a reductionist classical framework, it becomes very difficult to resolve these problems within the hypostatic union without resorting to an appeal to "divine mystery," in a manner that has distinct echoes of a "God of the Gaps" approach to theology. Not only does such a reductionist account therefore leave one with some seemingly insurmountable obstacles to forming a coherent account of the incarnation, but it also refuses to acknowledge the fact that "more than eight decades after the downfall of classical physics, the idea that the physicalist conception of nature, based on the invalidated classical physical theory, might be profoundly wrong in a way highly relevant" to this problem. ${ }^{9}$

9. Henry P. Stapp, "Quantum Reality and Mind," in Quantum Physics of Consciousness, ed. Subhash Kak, Roger Penrose, and Stuart Hameroff (Cambridge, Mass: Cosmology Science Publishers, 2011), 17. 


\section{Understanding Holism}

Ontological holism, at its most basic level, states that "in the last analysis, there is only one independent thing. Everything that exists is a way of being the one thing."10 Such a description may be all well and good for the philosopher, but for the theologian who believes God is a genuine part of reality, this sounds perilously close to a descent into Spinozism. However, it is possible to augment this initial definition with the popular explanation that a holistic system is "more than the sum of its parts." This combination of there being one fundamental reality, but that the fundamental reality has parts, marks holism apart from monism. The notion of "more than the sum of its parts" clearly implies a relational aspect to holism and it is this relational aspect that can been seen to augment our current understanding of Trinitarian relations. However we interpret holism though, it will impact upon how we understand the claim that "the Word became flesh and made his dwelling among us" (John 1:14), "since the children have flesh and blood, he too shared in their humanity" (Hebrews 2:14).

Having stated that one of the things that sets holism apart from monism is the belief that the holistic system had parts, it is necessary to briefly explain what is meant by the "parts" of holistic systems. I believe that "part" as understood in classical physics is not the same as "part" when used in terms of holism. I have said that a holistic system is more than the sum of its parts, but this cannot be the whole story, for it is easy to point to examples of atomistic systems that are more than their parts: a watch is more than the sum of its parts, if you take the watch apart you same the same collection of "parts" you had initially but you no longer have a watch. If you lay a pile of sand out grain by grain in a line across you floor, you no longer have a pile of sand yet you retain the same component parts. Both the watch and the pile of sand are created by the combination of the parts and, crucially the spatial and causal relationships between those parts; however, this relational "more than" is not enough to transform either into a holistic system, they remain atomistic systems. The reason for this is that holism requires a more meaningful "more than," the holism is not based in the arrangement but in the nature of system's parts, being a part of the holistic system must touch on the very nature of the object in question.

Bearing this in mind, it is now necessary to examine holism in more detail. Whilst claiming that ontological holism is necessary for the development of our theological discourse it is important to note that the two forms of holism to be examined provide very different contributions to our theological debate. Boolean holism accepts that the sum is more than its parts, but that crucially the whole does in fact have parts; it develops an intrinsically relational ontology that enables

10. Michael Esfeld, "Philosophical Holism," in Unity of Knowledge (in Transdisciplinary Research for Sustainability) Vol. 1., ed. Gertrude Hirsch Hardon (Oxford: Eolss Publishers, 2009), 120. 
us to deepen our current understanding and look beyond reductionism. NonBoolean holism, on the other hand, posits something far more radical that there are no parts, and reductionism is the result of our epistemic limitations. In order to address the impact both forms of holism may have in moving our dialo-gue forward, they will be explained in detail before some tentative suggestions are made as to how this may contribute to our theological discussion.

\section{Boolean Holism}

Boolean holism (also known as property holism) maintains that holism is the fact that "Some objects have properties that are not determined by physical properties of their basic physical parts."11 This is not a radical statement, and there is a long history of emergentist theories regarding the nature of mind, based in a belief that there is something genuine about our experience of a mental life that is not simply reducible to neuronal firing. What all of these interpretations point towards is an understanding of the world in which there are properties of complex systems that cannot be adequately explained by reductionism. The question therefore arises: in what sense does Boolean holism provide a new avenue for the theologian? Emergentism may work for the philosopher or scientist, but an implication that the only way to explain or understand the existence of an immaterial God is for that immateriality to have arisen from the complexity of the material world is not a theistic explanation. Additionally, the definition of property holism is quite specific, in that it deals with the physical properties of physical systems, so how can this help us to deal with the immaterial divine? The validity of property holism as a theological tool lies in the argument put forward by Esfeld that "many of the properties [...] taken to be intrinsic properties of physical systems are in fact relations."12

If our basic physical properties are in fact relational properties, then physicalism points to our fundamental ontology being one of holism rather than reductionism. In order to understand why these may in fact be relational properties we need to return to that atomistic exemplar the watch. As noted earlier, we appear to have two very different things with a working watch, and that same watch disassembled - there are properties that are not solely the physical properties of the parts i.e. relational properties. However, it is also possible for the reductionist to argue that what is instantiated in the working watch (over the pile of parts) is not some new physical property but in fact simply an unexpected relation on to which any new behaviour can be placed. Therefore, if physicalism is to remain as being about something more than relations it is necessary to place

11. Richard Healey, "Holism and Nonseparability in Physics," in The Stanford Encyclopedia of Philosophy, ed. Edward N. Zalta (Stanford: Stanford University Press, 1999), s3. Retrieved from goo.gl/hxEjhE.

12. Esfeld, "Physicalism and Ontological Holism," Metaphilosophy 30 (1999), 319. 
a limit on the "allowable" or fundamental relationships. The immediate candidate for this limiting factor would seem to be that the only defining relationships of the object are the spatial (or spatiotemporal) relationships. The individual parts can be understood as containing an "intrinsic, non-relational physical state"13 on to which all the physical properties of the object supervene. Under the reductionist credo it would be possible to reduce these large parts (gears, springs etc.) into a description of the relationship between the physical parts of that gear (for example), this analysis will reach its conclusion once we have arrived at parts that can no longer be divided. In order for the parts of this physical object to longer be divisible they must be unextended points, and so we find ourselves at field theory, whereby, under its classical permutation, every point in space has a physical quantity.

Yet it is possible to argue that physics is not ultimately concerned with the physical relational account of the world, but rather that physics is currently concerned with describing, what Esfeld calls the "functional dependence among physical systems."14 It is possible to argue that science fundamentally deals with quantities, understood as relational properties. Quantities are understood as relational properties as they allow scientists to makes comparisons between properties of different systems, for example it is possible to compare dimensions or weight between objects in a way that allows is to set those objects in relation to each other (as longer, heavier etc.). However, whilst it is possible to make relational statements about length or weight, this ability does not imply that the "functions" are in and of themselves relational; to do so would be to conclude that were there a universe containing only one object, that object could not have weight/shape/length etc. Therefore, one cannot claim a move to holism on the basis of rationality alone; or, at the very least, we must move away from considering relational properties as existing between multiple objects and instead consider relational properties as existing within a single object. It may seem that such a view is presupposing the existence of a holistic ontology, however, if we return to the unexpended points of the watch, it is possible to argue that even classical physics can be seen to point towards a Spinozan unity of matter.

The reason that Spinozan metaphysics posits a kind of holism that is relevant to our discussion of Boolean holism (and indeed reductionism) is because for Spinoza space is matter, and more crucially (classical) three-dimensional space is a continuum and this makes it inherently relational. In order for a point of space to exist there must be other points of space also in existence (it is a continuum), as Esfeld notes "what makes something a point or a region of space is relational

13. Tim Maudlin, "Part and Whole in Quantum Mechanics," in Interpreting Bodies: Classical and Quantum Objects in Modern Physics, ed. Elena Castellani (Princeton, NJ: Princeton University Press, 1998), 48.

14. Esfeld, "Physicalism and Ontological Holism," 320. 
properties or relations to other points or regions within the whole of space."15 What this means for a holistic ontology is that whilst the properties may be properties of the whole (of space) they actually refer to the internal structure of that whole. This is not to imply that space exemplifies two different properties simpliciter (i.e. that is both pebbly and watery), but rather that at point $x$ it has the property of being pebbly, and at point $y$ it has the property of being watery. Whilst it is possible to say that space as a whole has these properties, what the properties actually do is define different points or regions within that one space.

It may seem that this descent into Spinozism has erred off topic but in fact the notion of space and space points forming a continuum is very much at the heart of why ontological reductionism fails when taken to its extreme. Taken to its extreme, reductionism leads to some form of field theory - the idea that space is made up of an infinite number of space(-time) points all standing in relation to one another. This is because until an object is reduced to an unextended point, it can still be reduced further. However, if we fully accept a form of field theory in which every region of space "is specified by the attribution of a physical quantity"16 it would appear that we have arrived a potentially a truly radical holism in which no portion of space(time) can be described without reference to every other portion of space(time) i.e. the entirety of the universe. This is a far cry from the aims of reductionism and yet it appears that taken to its full conclusion reductionism leads to a form of Boolean holism.

\section{Non-Boolean Holism}

Whereas Boolean holism examines the relationships between the parts of the system, Non-Boolean holism examines the very system itself. In Non-Boolean Descriptions for Mind-Matter Problems ${ }^{17}$ Primas sets out a "framework for the mindmatter problem in a holistic universe which has no parts." 18 He claims our current understanding of mind-matter is based on a tacit acceptance of classical atomism $^{19}$ and, as I have already noted with respect to the incarnation, this assumption has serious knock-on implications for our undertanding of the issues concerned. Primas bases his need for Non-Boolean descriptions in the fact that quantum mechanics has shown atomism to be incorrect thus causing reductionism to fail. Therefore, we need to acknowledge that our reductionistic

15. Esfeld, Holism in Philosophy of Mind and Philosophy of Physics, Synthese Library, vol. 298 (Dordrecht, Boston: Kluwer Academic Publishers, 2001), 176.

16. Maudlin, "Part and Whole in Quantum Mechanics," 48.

17. Hans Primas, "Non-Boolean Descriptions for Mind-Matter Problems," Mind and Matter 5 no. 1 (2007).

18. Ibid., 7 .

19. Classical atomism is used here to refer to the reduction of objects into distinct, separable, and independent elementary components, not the atomism adopted by the ancient Greeks. 
descriptions represent our own epistemic imitations rather than a fundamental ontology. At this level of description, non-Boolean holism sounds similar to Spinozan metaphysics - after all for Spinoza all matter is the same, "except in as far as we regard it as affected in different ways, parts are not distinguished in it; that is to say, they are distinguished with regard to mode, but not with regard to reality." 20 The difference with a non-Boolean description of the world as proposed by Primas, is that it does not rely on Spinoza's argument that "in nature there cannot be two or more substances of the same nature or attribute."21

Instead, Primas examines the world described by quantum physics and the way in which classical (Boolean) descriptions fail to adequately account for the quantum world. Classically Boolean classifications are made on the basis of shared attributes of individual objects, on the assumption that both individual objects exist and that they have well defined attributes. Whilst none of these classifications are unbiased, they can all be described in Boolean terms and they can be understood to be compatible or incompatible with one another depending on whether they can be encompassed within a single common Boolean classification. The crucial point to be made here is that whilst it is possible to combine some compatible classifications into a single Boolean description, what it is most assuredly not possible to do is to combine the totality of all experiments, or classifications, into a single Boolean description.

Boolean classification allows for the description of the world in terms of duality, whereas non-Boolean classification allows for the description of the world in terms of complementarity. The greatest example of the difference between these descriptions lies in the concept of wave-particle duality. When understood as a duality it allows for the fact that photons exhibit properties of waves and particles, in other words, waves and particles fall into separate Boolean categories. The problem with this description is that we now know that whilst they can be wave-like and/or particle-like photons can also exhibit an infinite number of other states that do not fall in to the two discrete categories. Because the description is not one of "well defined" attributes we were wrong to class it as a duality and should instead be classing it as complementarity.

To say that the statement is complementary rather than dualistic is to claim that it describes a holistic situation "where Boolean fragmentation into parts is not possible."22 Complementarity allows us to describe a world in which Boolean classification does not work; at the ontological level, it acknowledges the fact that in principle it is possible to know everything about the conditions of a particular experiment or a particular region of space, but it is not possible to know everything simultaneously. This may sound like an extremely flippant statement, of course we cannot know everything at once we are not omnipotent; but this

20. Benedictus de Spinoza, Ethics (Ware: Wordsworth Editions, 2001), 17.

21. Ibid., 5.

22. Primas, "Non-Boolean Descriptions for Mind-Matter Problems," 15. 
claim is not about omnipotence it is a claim about the evidence it is possible to collect in a single experiment. For example, whilst it may be in principle possible to measure both the location and the momentum of a particle it is not, according to Heisenberg's Uncertainty Principle, possible to know both at the same time. What this means is that our discourse, whether theological or scientific, needs to be expanded to allow for complementary descriptions and that in doing so we need to actively acknowledge that the complementary description "refers always to a contextually chosen decomposition of the universe of discourse,"23 it is not describing an ontological state of affairs.

Perhaps the best example of the effect of moving towards a non-Boolean holistic account of the world lies in the implications for the "paradox" of entanglement. ${ }^{24}$ Given that entanglement is often cited as a useful analogy for Trinitarian relations it starts to provide an insight in to the potential theological implications of adopting a holistic ontology. In our everyday understanding of the world we believe that certain objects are independent of one another - that there exists an ontological separation through time and/or space. We understand two objects to be "separate" if an experiment performed one does not impact upon the state of the other, and in viewing separability as something self-evident in nature the curious effects of experiments on "entangled" objects provide us with a paradox. The earlier description of property holism spoke of the physical properties of physical systems; however, in a genuinely holistic world where physical and mental are not ontological distinctions, "genuine holistic correlations are not restricted to physical systems"25 because the description of the world is not based in an atomistic world full of parts the correlations are in fact no more than a contextual concept rather than an ontological anomaly. This is because a system that is genuinely describable through Boolean logic does not create "entanglement," "entanglement" is created when a Non-Boolean system is divided into parts, furthermore the level of entanglement is subject to change depending on how the system is partitioned.

What a Non-Boolean ontology leaves us with therefore, is the need to recognise that our partitioning of the world, just like our decisions about what is "irrelevant" for any one experiment, are not based in natural laws, or genuine features of nature but in a human decision or bias. They are based in the

23. Ibid., 16.

24. The paradox of entanglement refers to the EPR thought experiment (EinsteinPodolsky-Rosen Paradox). A spin 0 particle decays into two different particles, Particle A and Particle $B$, heading in opposite directions. Due to the spin state of the initial particle the combined spin of the two new particles must equal 0. If Particle A has spin $+1 / 2$, then Particle B must have spin $-1 / 2$ (and vice versa). Once we have a measurement for Particle A, we also have certainty for the spin of Particle B. The apparent paradox is that it seemingly involves "action-at-a-distance" or greater than light speed communication between the two particles.

25. Primas, "Non-Boolean Descriptions for Mind-Matter Problems," 28. 
limitations of our measuring equipment and the information that we wish to portray. That is not to say that our language does not still have a place for Boolean descriptions, but that when we speak in Boolean terms we have to acknowledge that we are not speaking about the way the world is, but about a particular experiment, region of space, or object in isolation. What it is possible to do, however is to combine multiple Boolean descriptions in such a way that they overlap in order to provide us with a partially Boolean description. For example, different cartographic projections provide us with a different Boolean representation of the world. They are able to preserve some, but not all, of the details in isolation. The Mercator projection preserves angles and circles and is used in aeronautical charts, but presents the world as a flat surface; the stereographic projection preserves shapes and directions and is used in the polar regions, however area becomes more distorted the further from the centre of the circle one moves; the Lambert azimuthal projection preserves areas but the further one moves from the centre of the map the greater the distortion of shape. When taken in isolation, each projection has sacrificed that which is deemed irrelevant for its purposes, and none is able to provide a fully accurate representation of the way the world actually is. Yet, if all of these projections are combined, pasted together as it were, they would enable us to see the totality of the information available to us.

Just as it is possible to combine multiple projections to provide a global picture in the case of the maps, it is also possible to do the same with our Boolean descriptions of the nature of the world - we need to create what is called as Boolean atlas. A Boolean atlas is formed of families of Boolean descriptions called Boolean charts. These charts then overlap in such a way that when they overlap they are compatible. The combined information contained within a Boolean atlas is able to provide all the information required for a non-Boolean description. Where the Boolean charts overlap, they will appear to be locally Boolean, even though taken as a whole they are globally non-Boolean. These locally compatible areas of the Boolean atlas can be defined through partial Boolean descriptions in which the overlapping elements can be said to have a common Boolean subdescription. However not every pair of elements within the overlapping collection will belong to the same sub-description. What this breaks down to is the fact that even when there is a local overlapping the overlapping itself cannot be quantified in a single Boolean description rather there is complementarity involved at the local level meaning that not all of the descriptions will apply to all of the pairs. 


\section{Some Tentative Suggestions for Holistic Ontology}

\section{Boolean Holism}

The key to Esfeld's conception of holism rests in the nature of parts and their relational properties, he defines a holistic system as:

Consider a system of the kind $S$ and its constituent parts [...] An $S$ is holistic if and only if the following condition is satisfied by all the things which are its constituents: with respect to the instantiation of some of the properties that belong to such a family of properties, a thing is ontologically dependent in a generic way on there actually being other things together with which it is arranged in such a way that there is an $S .26$

This marks Esfeld's relational holism out as a form of Boolean holism. By Boolean holism I am not implying a binary conception of parts, but rather a form of holism that allows for the existence of parts within a holistic system. When placed in these terms, it is possible to see an immediate comparability with our conception of both the Trinity and the hypostatic union - both are to be understood as complex wholes that contain parts. However, the key to this discussion is that "parts" as understood within holistic systems is not to be understood in the same manner as "parts" within our everyday reductionist usage, this is because "parts" when used with respect to this conception of a holistic system does not imply independent existence outside of the whole.

\section{A Bottom-Up Account of the Incarnation}

Whether an account is to be taken as an example of bottom-up or top-down holism depends on the manner in which one elaborates the definition of holism with respect to the phrase "with respect to the instantiation of some of the properties that belong to such a family of properties." ${ }^{27}$ In the case of the bottomup account one begins with the constituents of the holistic system $(S)$ and the properties that make them constituent of $S$. Something can have some of these properties if there are other things with which it is arranged, such that there is an $S$. In other words, if the whole has particular properties, it is because the constituents have them. This means that the properties themselves do not imply any form of individuation within the complex whole, and the only way in which the whole is able to exhibit particular properties is because they are instantiated by the parts. Whilst it may be possible to argue for a level of supervenience of the "global" properties on the "local" properties, there is no necessary implication of a metaphysics of supervenience in this instance. In what follows, I will examine

26. Esfeld, Holism in Philosophy of Mind and Philosophy of Physics, 1.

27. Ibid., 17. 
why the bottom-up conception of holism does not necessarily imply supervenience and how it can lead us to a deeper understanding of the incarnation. The key feature of holism for this discussion is that it allows one complex whole to contain various constituent parts and, crucially, that these constituent parts may have properties that belong to different "families" (of qualitative, non-disjunctive properties that make something a constituent of $S$ ).

In applying this ontology to the incarnation, the first question that needs to be answered is to what are we attaching the role of a "holistic system" $(G)$ ? Whether we are attaching this to Christ or the Trinitarian God will impact how we understand its implication. In order to establish the "boundaries" of our system it is necessary to return to the definitions of atomism and holism. In atomism the parts of the whole hold properties independently of one another, with the properties of the whole being formed of the aggregate of the properties of the parts. Conversely in holism the parts of the whole hold properties in virtue of being within the whole itself. For example, a grain of sand has specific properties that make it a grain of sand (this include chemical make-up, mass within certain boundaries etc.), the grain of sand has these properties irrespective of whether it is part of a heap of sand (itself an atomistic system). These properties (of the grain of sand) can be held even if $x$ is the only physical object in a possible world. If the "heap of sand" was a holistic system, then it would only be possible for the grain of sand to have the particular properties (that define it as such) as a part of the heap of sand and therefore it would be impossible for $x$ to be the only existent object within a possible world. Therefore, in order to establish whether it is Christ or God that constitutes our whole, one needs only to establish whether it is Christ or God that could be the solely existent object within a possible world. It is possible to argue that whilst the Word was pre-existent "Christ" was not and could not be a solely existent object simply because the definition of what it is to be Christ requires the existence of more than one object Christ is God incarnate, therefore irrespective of whatever model of the incarnation one chooses to adopt the existence of Christ, at a bare minimum, requires the existence of God and the existence of a physical body. This would therefore imply that it is God that is our holistic system and not Christ. Furthermore, the incarnation is traditionally seen as a contingent event "the Son of God became incarnate in our world, but it was not necessary that he do so; there are possible worlds in which no incarnation takes place." 28 This again reaffirms the understanding that Christ is dependent upon something else outside His inherent unity for His existence.

This talk of God and Christ as "systems" and "wholes" may seem particularly untheological, as if the notions of God and Christ have been abstracted beyond

28. Thomas P. Flint, "Should Concretists Part with Mereological Models of the Incarnation?," in The Metaphysics of the Incarnation, ed. Anna Marmodoro and Jonathan Hill (Oxford: Oxford University Press, 2011), 73. 
the traditional understanding of what is meant when we use them in a religious context; however, this is not meant to be the case. In order to understand how a holism that allows for parts can contribute to our theological discussion it is necessary to first establish the "parts" of our holistic system. In establishing, unsurprisingly perhaps, that Christ is a "part" of God the "whole" there is a danger that this exploration will become side-tracked by a discussion of Trinitarian models of God, which obviously moves beyond the scope of this paper. As previously mentioned it is possible for both the bottom-up and topdown approaches to speak in terms of a metaphysics of individuals, and when the question of individuals is brought in to play regarding the incarnation it can be seen to run the risk of falling afoul of Nestorianism. This risk occurs because, under an orthodox understanding of the incarnation, that which is assumed by the Son in becoming Christ would, if left unassumed have been able to be understood as a full human person. If we are unable to say that Christ's human nature could have constituted a genuine human person, we appear unable to truly say that Christ was "fully man." However, in claiming that Christ assumed something that was "fully man," we also appear to be teetering on the edge of claiming that Christ was two distinct persons (Nestorianism). In order that one is able to allow for "individuals," without allowing for Nestorianism, room has to be made to deny the (independently existing) "personhood" of Christ's human nature. Whilst the details of this particular debate are not strictly pertinent to this discussion, Flint's ${ }^{29}$ explanation of the parts involved does offer a way to examine Christ as a part of "complex system" that is God, without having to engage in a deeper discussion of Trinitarian theology.

In Christ we find two unique natures the human nature $(\mathrm{HN})$ and the Son's divine substance (DS), so far this is not problematic, however if "the Son" (preand post-resurrection) is identical with the divine substance then, given their consubstantial existence, the DS in the incarnation must also be identical with the Father and Holy Spirit. Without this distinction, then we cannot allow the persons of the Trinity to be distinct, rather they become no more than three aspects of the one God. In order to avoid both an indistinct Trinity and an in-depth Trinitarian discussion Flint adopts the following definition of DS as "stan-ding for the divine substance plus whatever properties or characteristics (e.g., being generated by the Father) distinguish the Son from the other two divine persons."30 The pluswhatever clause allows for enough of an understanding of DS that the discussion can continue, but avoids getting tied down in the details of the exact nature of the DS or the additional properties and their relations. I am hopeful that the adoption of Flint's definition allows this paper to progress in a similar manner, at least with respect to Boolean holism it remains to be seen whether the same approach will be applicable to a non-Boolean discussion.

29. Ibid., 71.

30. Ibid. 
With the bottom-up approach the discussion must start with the nature of the parts of $G$ (remembering that $G$ is the Trinitarian God). It is entirely possible for a complex whole to consist of "parts" requiring different "families" of properties that account for their constituting the whole. The anthropological equivalent would be the human body - there are many organs/systems that constitute the human body. These organs/systems cannot be understood as constituting a human body without being in the correct arrangement with other parts. However the family of properties that constitute a liver "part" is very different to the family of properties that constitute a brain "part" and so on. ${ }^{31}$ Whilst this may sound like an atomistic approach, ${ }^{32}$ it is holistic in that it the constituents of the whole are constituents not because of some accidental relational property, but because they contain holistic properties - properties that cannot be held without there being other "things" that combine with that part to create $G$. The key is that the properties that make a constituent do not all have to be holistic properties, and those properties that are deemed holistic can be more or less essential to the identity of the system as a whole.

Having understood the notion familial properties for a human example, how then are we to understand the notion of familial properties with respect to the

31. It is possible to disagree with my definition of a human person as a holistic system on the grounds that a functional definition of the organs does not establish that the human organism is a holistic system. It is possible to produce functional individual organs in isolation from the human organism itself and therefore they do not require a "suitable arrangement." In response to this I would argue that I am not seeking to define the human organism in functional terms, I do not think that it is necessary for the "functions" of different organisms to be carried out individually either by biological or artificial organs in order to make the case for a human person existing. However I do believe that in order for a human organism to be considered a human person there is a sense in which the properties that make the parts of a human "constituents of" that system are entirely ontologically dependent upon there being other things (whether mechanical or biological) that are arranged in such a manner that there is a holistic system. Alternatively it is possible to argue that something can only be said to exhibit a holistic property if, when it is instantiated, there are many objects that instantiate the same property(ies). Esfeld's particular definition of a holistic system allows for variability in the number of times a family of properties that make something constituent of a system are instantiated in that system. This means that it is possible to understand an organism as a holistic system despite the fact that each family of properties may only be instantiated once or twice within a single organism. The advantage to using the example of a human person is that is readily allows for the discussion of non-contentious "parts" that are not overly complicated by questions about the transitivity of their properties, but allow for an uncomplicated understanding of the nature of families of properties. There is no implication in the use of the anthropological example that there is an analogy between God and the body/world. It is purely for illustrative rather than analogical purposes.

32. An atomistic approach refers to interpreting/understanding objects by analysis into distinct, separable, and independent elementary components. 
incarnation? The obvious, and perhaps most defined, family of properties would appear to be divine characteristics. Even if one wished to avoid all denominational differences and limit these solely to omnipotence, omniscience and omnibenevolence we still appear to have a strong set of properties that makes something a constituent of the divine G. However, can these properties, definitive of the divine though they may be, truly be considered as holistic properties? In order for a property to be holistic, "nothing can have this property unless there actually are other things together with which this thing is arranged in such a way there is an [G]."33 None of these properties actually require a Trinitarian conception of God, the omniscience of DS in Christ is not dependent upon a Trinitarian God. It may be that omniscience is an essential property of DS or even of God but essentialism does not imply holism. In order to be holistic, the property must be a (special kind of) relational property, and it is not immediately clear that the Omni properties are relational in the correct way. It is entirely possible, of course, to argue that the omni properties above are relational properties: omniscience requires something to be the subject of that knowledge, omnibenevolence requires something to love, omnipotence implies something over which power can be exerted.

However, in order for the relations exhibited by the omni properties to be considered as holistic relations they necessitate the existence of objects to which the relation applies, which would appear to make God dependent on the existence of some form of creation, or at least the possibility for creation. Furthermore, it could be argued that the omni properties are simply relational properties and, as such, are not the correct kind of property to which it is possible to ascribe holism. In order for a holistic property to be more than a relational property, it is "necessary that the description of the property cannot be reduced to a description of nonrelational properties and the description of a suitable arrangement." 34 For example, it is possible to reduce the property or omniscience to a property of "being able to have unlimited knowledge" and the interrelation between the ability and the objects of that knowledge.

If omni-properties are not the correct kind of properties to be holistic properties of $G$, then what kind properties are required? The key determining factor in establishing holistic properties is that "the 'more than the sum of its parts' does not mean a specific spatial or causal arrangement of the parts, but that being part of the system touches on the nature of the thing in question." 35 Therefore, when it comes to God, the property that most touches on the very nature, without implying an external contingent relationship is the property (or properties) of being part of a Trinitarian Godhead. Being a part of the Trinity is not an arrange-

33. Esfeld, Holism in Philosophy of Mind and Philosophy of Physics, 17.

34. Ibid., 19.

35. Esfeld, "Philosophical Holism," 122. 
ment property in the traditional sense; it is not reliant on spatial or temporal relations, and yet it cannot be reduced to a non-relational property either.

There is a risk in understanding this "Trinitarian" property ( $T$-property) as a holistic property, and this lies in whether it can be said to point towards a nontrivial form of holism. The holism becomes trivial if the $T$-property is understood as simply being "the property of being a constituent of a Trinitarian Godhead" this is because by our current definition of a holistic system it is necessary for there to be a "suitable arrangement" of the constituent parts. Personally I feel that that the fact that it is a "Trinitarian" property rather than simply the property of "being a divine being" means that the property necessarily contains the "suitable arrangement" without it being reducible to non-relational properties plus arrangement. Whilst it may not be possible, particularly within the scope of this paper, to examine the exact nature of this $T$-property, just as with the pluswhatever clause of the DS it should provide enough of a working definition to enable the discussion to move back towards the incarnation.

So far it has been established that Christ consisted of a HN and DS, and that the DS contains the $T$-property which makes it a holistic part of the Godhead $(G)$. However, whilst the $T$-property may account for how the DS is related to $G$ it does not account for how the HN can be united with the DS to form a constituent part of $G$. In order to explain this on the basis of the bottom-up approach something more is needed. In the original discussion of the nature of constituent properties, it was mentioned that it was possible for different constituents to have a different family of properties that make it a constituent of the whole. Such a system would allow for the family of properties relating to DS to be slightly different, depending on whether they related to the Father, Son or Holy Spirit; alternatively, not all the properties instantiated by the constituent have to be holistic properties, so it could be possible to argue that the DS (including the $T$ property) forms the family of properties that an object must have in order to be a constituent of $S$, but that the individual plus-whatever properties are not to be viewed as holistic properties themselves.

It might seem that the obvious solution to ensuring that $\mathrm{HN}$ is united with the DS in Christ is to simply say that the properties of $\mathrm{HN}$ form an additional part of the plus-whatever entailed by being the Son. However, to do so would seem to imply that $G$ also exhibits the properties of $\mathrm{HN}$, and after all the whole exhibits particular properties because the constituents have them. To return to the earlier anthropological example, the human person as a holistic system has the property of being able to filter toxins out of the bloodstream because the constituent part "liver" has these properties (in respect to being arranged in a certain way with other things such that there is a human person). It would seem beyond troublesome to create a holistic model of the incarnation that led to the DS in general, or $G$ in particular, consisting of human properties.

Thus, it appears necessary to investigate more fully the constituent that is called Christ, and how this can be understood as a single constituent of $G$. The 
family of properties that make HN and DS parts of Christ cannot include the property "being a constituent of Christ," because to do so is to trivialise the notion of holism, just as if the $T$-property had been "being a constituent of the divine." In trying to identify this property or properties it might be tempting to conceive of Christ as a secondary holistic system $C$ that can be understood as being a part of the greater holistic system $G$. Whilst this move might be tempting at an epistemic level, it fails to work at the ontological level. The holistic properties have to touch on the very nature of the object in question, and whilst it is possible to argue that containing $\mathrm{HN}$ touches on the very nature of system $C$ the same cannot be said for system $G$ of which it is a part. Ultimately the best that can be said of the bottom up approach is that it provides an alternative reasoning behind assigning properties via the Qua-propositions in a way that is less ad-hoc. However, it fails to genuinely overcome the problems associated with more traditional compositional accounts of the incarnation.

\section{A Top-Down Account of the Incarnation}

The top down approach allows that properties exhibited by the whole are only able to do so when two or more constituent parts are arranged in an appropriate manner. Therefore under this approach, rather than beginning with the properties that make an individual constituent part of a holistic system, it begins with properties that can only be considered as existing when several (not necessarily all) the constituents are examined together. What this means is that whereas in the previous model the property (or family of properties) that made an object a constituent of $S$ could be instantiated by an isolated individual, the properties examined here cannot - they are instantiated by the whole. However, Esfeld notes that these properties "introduce constituents by indicating the way in which constituents are related with respect to the properties in question." 36

Bearing this definition in mind, it would seem that under a top-down approach, the holistic system $(G)$ we are examining is the Trinitarian God rather than Christ. The reasoning in this approach remains similar to the bottom-up account, in that the constituents of Christ can be instantiated in isolation, whereas the properties of a Trinitarian God, by definition, require that there are parts arranged in a certain manner. The properties being examined under the topdown approach then become the $T$-properties mentioned earlier, and in fact it could be argued that just are there are $T$-properties that relate to the godhead as a whole, it may be argued that there is a particular kind of Incarnational or Iproperty that refers to how the properties of DS and HN relate within the person of Christ in a manner that cannot be understood when the properties are taken in isolation. After all, it would seem inherent in the nature of incarnational

36. Esfeld, Holism in Philosophy of Mind and Philosophy of Physics, 25. 
properties that they point towards how the constituents of HN and DS are related to each other and instantiated in the whole.

The top-down approach allows for novel properties to arrive out of holistic systems, due to the complexity and relations between the constituent parts in a manner that perhaps is not allowed quite so explicitly in the bottom-up approach. It also appears that it may allow for there to be particular properties associated with the incarnation that are not associated with the godhead as whole, perhaps through recognising Christ as a "sub-system" of sorts. However, whilst it allows for a certain level of irreducibility at the level of the whole, it still at least on an initial inspection, allows for a sectioning off of the individual components (father, son, holy spirit). The most problematic aspect of this partitioning is that it appears to occur at an ontological or quasi-ontological level, leaving us with ways of understanding the three, but not the one. It can be argued that the issues associated with the bottom-up and top-down approaches are associated with the adherence to a metaphysics of individuals. In his 2004 work, Esfeld explains how a metaphysics of relations may be understood. A metaphysics of relations denies the assumption that in order for things to stand in relation they must have properties over and above their relations. By "thing" there is no necessity for these to be independent things - whilst properties can be predicated of things, things cannot be properties of something else. This relational ontology provides the opportunity to avoid the issues associated with individuals in relation to the incarnation (in particular concreteism ${ }^{37}$ ), however whilst it does allow for objects (as bundles of properties [tropes]) to exhibit haecceity this requires additional properties. An ontology of relations seems to capture something of what it is for HN and DS to be united in Christ, but it does not seem to be able to provide any theological advantage; it could be that further exploration of the practicalities of relational ontology may provide opportunities for theological development, however, such an exploration goes beyond the scope of this paper.

\section{Non-Boolean Holism}

In discussing the direction non-Boolean holism may take our theological understanding, we are faced with unique problems that are not presented by Boolean holism. The first of these is that whilst not engaging with the theological implications, Esfeld does examine in detail the kind of metaphysics he understands as being posited by holism, and indeed how this may be arrived at whilst maintaining a reductionistic account of the world. We do not have the same information from Primas' philosophy; rather, what we have is a description of how it may relate to the mind-body problem, but not what kind of fundamental

37. Concreteism is the claim that the incarnate Son of God assumed a "concrete created individual." In other words without the inclusion of the Son of God if the individual had it existed on its own it would have qualified as a full human person. 
"stuff" we can expect from this reality. We have no way of knowing if this would have been developed in due course, but it does leave a challenge in moving our metaphysics forward.

One possible way of overcoming this metaphysical detail is to start by looking to other possible descriptions that may be seen as providing a holistic metaphysics, and one that I believe is promising, is proposed by William Dembski. ${ }^{38}$ Dembski argues for a metaphysics in which the fundamental substance is not matter, but information. More specifically, Dembski argues that the world is not ultimately founded on particles, but "the information that passes between entities - entities in turn defined by their ability to communicate information."39 Thus, for Dembski what is real is defined by what can communicate; thus, "things exist in so far as they interact via information with other things." 40 Dembski's informational realism, however, does not necessitate informational monism and, in parallel with Esfeld, it promotes a relational ontology. Whilst Dembski does not require a fundamental monism (or holism), the non-Boolean metaphysics promoted by Primas does; and it is difficult to conceptualise how me may understand God as information. Dembski avoids this by arguing that informational realism can allow for objects that are not themselves items of information, such as the Judeo-Christian God, but this would appear to be a return to a different kind of dualism and all the associated issues that produces. To this is end, I do not feel that unaltered informational realism provides an appropriate understanding of a non-Boolean metaphysics. However, I do feel that non-Boolean holism does offer us a way to break through our problematically dualistic metaphysics to arrive at a new understanding of what we mean when we say "Not Three Gods; but One."

\section{Conclusion}

In the course of this paper I have examined two very different models of holism that have the potential to bring our theological metaphysics in line with our current scientific understanding of the nature of the world. There is no doubt that more work needs to be done on this area, and my own continuing research seeks to develop our understanding of non-Boolean metaphysics further. However, what strikes me most about our options for a holistic ontology is that the Boolean approach at present seems to provide only a re-orientation of our current way of thinking, another explanatory tool to be used in conjunction with the qua-propositions. In stark contrast, a non-Boolean approach provides us with a re-

38. William A. Dembski, Being as Communion: A Metaphysics of Information (New York: Ashgate Publishng, 2014).

39. Ibid., xiv.

40. Ibid., 197. 
founding of our theological understanding. When I speak of re-founding our understanding, what I mean is that we radically re-orient our beliefs upon a new foundation, and in doing so put aside our current assumptions. Non-Boolean holism is not without its problems, and the most pertinent of these is how we are to understand individuation within the Trinity and Christ incarnate. However, I believe that continued exploration of holistic theology will enable us to reach a greater understanding of what we mean in speaking of our divided yet unified God; and it is in a non-Boolean or 'partless' holism that we will find our answers.

\section{Bibliography}

Ayala, Francisco J. "Biological Reductionism." In Self-Organizing Systems, edited by F. Eugene Yates, Alan Garfinkel, Donald O. Walter, and Gregory B. Yates. New York: Springer, 1987.

Dembski, William A. Being as Communion: A Metaphysics of Information. New York: Ashgate Publishng, 2014.

Esfeld, Michael. "Philosophical Holism." In Unity of Knowledge (in Transdisciplinary Research for Sustainability) Vol. 1., edited by Gertrude Hirsch Hardon, 120. Oxford: Eolss Publishers, 2009.

Holism in Philosophy of Mind and Philosophy of Physics, Synthese Library, vol. 298. Dordrecht, Boston: Kluwer Academic Publishers, 2001.

"Physicalism and Ontological Holism." Metaphilosophy 30 (1999), 319-337.

Espagnat, Bernard d'. Veiled Reality: An Analysis of Present-Day Quantum Mechanical Concepts. Boca Raton, Florida, United States: CRC Press, 2003.

Flint, Thomas P. "Should Concretists Part with Mereological Models of the Incarnation?." In The Metaphysics of the Incarnation, edited by Anna Marmodoro and Jonathan Hill, 73. Oxford: Oxford University Press, 2011.

Healey, Richard. "Holism and Nonseparability in Physics." In The Stanford Encyclopedia of Philosophy, edited by Edward N. Zalta, s3. Stanford: Stanford University Press, 1999. Retrieved from goo.gl/hxEjhE.

Leftow, Brian. "The Humanity of God." In The Metaphysics of the Incarnation, edited by Anna Marmodoro and Jonathan Hill. Oxford: Oxford University Press, 2011.

Macquarrie, John. God Talk: Examination of the Language and Logic of Theology. London: SCM-Canterbury Press, 1970.

Maudlin, Tim. "Part and Whole in Quantum Mechanics." In Interpreting Bodies: Classical and Quantum Objects in Modern Physics, edited by Elena Castellani, 48. Princeton, NJ: Princeton University Press, 1998.

Primas, Hans. "Non-Boolean Descriptions for Mind-Matter Problems." Mind and Matter 5, no. 1 (2007), 7-44.

Spinoza, Benedictus de. Ethics. Ware: Wordsworth Editions, 2001. 
Stapp, Henry P. "Quantum Reality and Mind." In Quantum Physics of Consciousness, edited by Subhash Kak, Roger Penrose, and Stuart Hameroff. Cambridge, Mass: Cosmology Science Publishers, 2011.

Wittgenstein, Ludwig. Tractatus Logico-Philosophicus. Translated by C. K. Ogden. London: Edinburgh University Press, 1922. Retrieved from goo.gl/EoycUy. 
